\title{
Oral contraceptives and tryptophan metabolism: Effects of oestrogen in low dose combined with a progestagen and of a low-dose progestagen (megestrol acetate) given alone
}

\author{
D. P. ROSE AND P. W. ADAMS
}

From the Alexander Simpson Laboratory for Metabolic Research, St Mary's Hospital Medical School, London

SYNOPSIS The effect upon tryptophan metabolism of the use of combined oestrogen-progestagen oral contraceptives containing a low $(0.05 \mathrm{mg})$ dose of oestrogen, or of the continuous administration of megestrol acetate, has been studied by determining the excretion of tryptophan metabolites in urine collected after a $2 \mathrm{~g}$ oral dose of the amino acid.

An investigation of 10 women before being given oral contraceptives and after 21 days and three months of their use showed that xanthurenic acid excretion is increased within 21 days and that by three months the urinary levels of xanthurenic acid, kynurenine, 3-hydroxykynurenine, and 3-hydroxyanthranilic acid may all be elevated.

Ten other women studied after taking a combined type of oral contraceptive for six months or longer excreted significantly higher levels of all four metabolites than did those who had been treated with these steroids for only three months. The abnormal urinary excretion of tryptophan metabolites was completely reversed by treatment with pyridoxine hydrochloride, $20 \mathrm{mg}$ daily for one month.

Studies of four women when they were taking an oestrogen-containing oral contraceptive and at intervals after they had discontinued its use showed that abnormal tryptophan metabolism may persist for three months or longer.

Megestrol acetate, a progestagen used as an oral contraceptive, was found to have no significant effect upon tryptophan metabolism.

The possible clinical significance of the effects of oral contraceptives upon tryptophan metabolism is discussed.

There have been several reports of disturbed tryptophan metabolism in women using oral contraceptives, the abnormality being characterized by an elevated excretion of xanthurenic acid and other metabolites of the tryptophan-nicotinic acid pathway (Fig. 1) in urine collected after an oral dose of the amino acid (Rose, 1965, 1966; Price, Thornton, and Mueller, 1967; Luhby, Davis, Murphy, Gordon, Brin, and Spiegel, 1970). These changes are similar to the altered excretion of tryptophan metabolites which occurs in vitamin $\mathbf{B}_{6}$ deficiency, they are reversed by treatment with large doses of pyridoxine, and they are also present in patients treated with oestrogens alone (Brown, Rose, Price, and Wolf, 1969).

Received for publication 13 September 1971.
The clinical significance of the disordered tryptophan metabolism produced by oestrogens remains to be established, but, as will be discussed later, it may be related to two recognized complications of the use of oral contraceptives-mental depression and impaired glucose tolerance.

The women studied in previous investigations were using a combined oestrogen-progestagen type of oral contraceptive, and the majority were receiving a high dose of oestrogen $(0.075$ to $0.1 \mathrm{mg})$. Rose (1966) did report abnormal tryptophan metabolism by five women taking a preparation containing only $0.05 \mathrm{mg}$ ethinyl oestradiol, but the $5 \mathrm{~g}$ dose of L-tryptophan which he used in his original study is equal to approximately five times the normal daily dietary intake of this amino acid, and is therefore a 


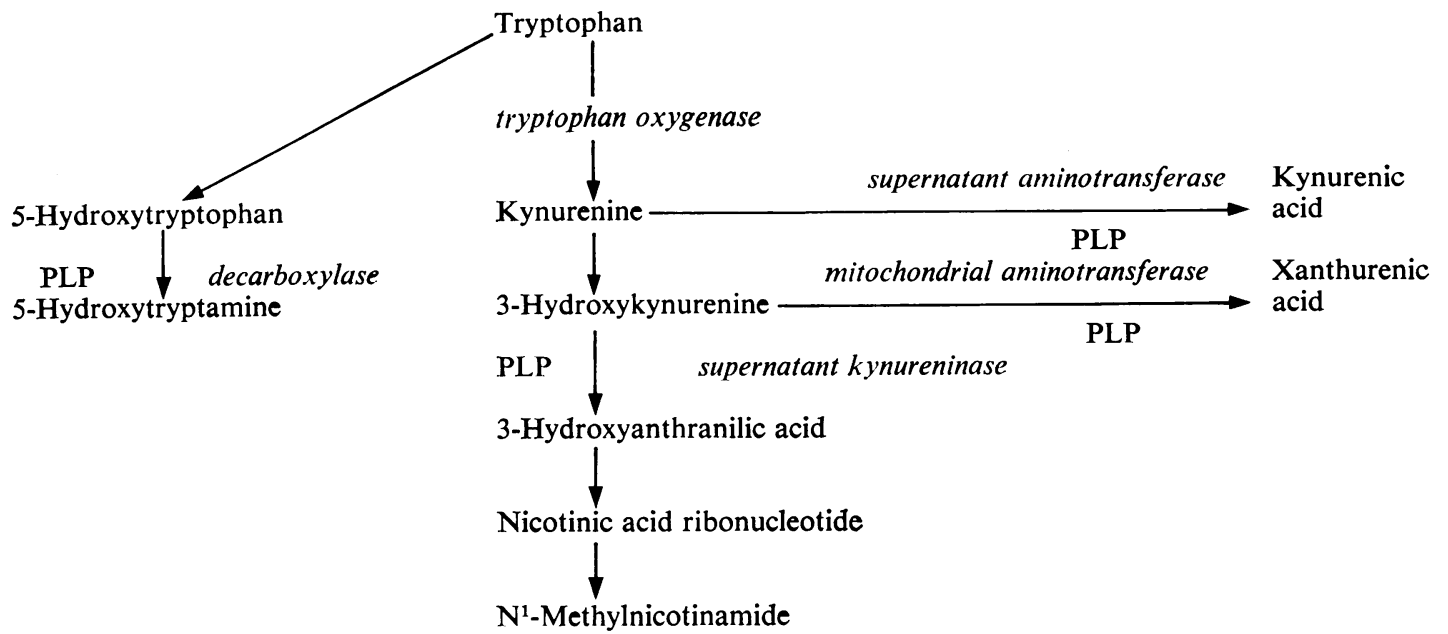

Fig. 1 The metabolic pathways for the biosynthesis of nicotinic acid ribonucleotide and 5-hydroxytryptamine from tryptophan. (PLP indicates pyridoxal phosphate dependent enzyme reactions.)

grossly unphysiological load. The advantages of using a $2 \mathrm{~g}$ tryptophan load have been discussed by Price, Brown, and Yess (1965).

Since the recommendations of the Committee on Safety of Drugs (Scowen, 1969) the dose of ethinyl oestradiol or its 3-methyl ether, mestranol, in the combined oestrogen-progestagen oral contraceptives now in common use in the United Kingdom has been limited to $0.05 \mathrm{mg}$. Clinical and biochemical investigation of continuous low-dosage progestagen preparations given alone indicate that these steroids provide an alternative form of oral contraception which is moderately efficient and is not associated with significant metabolic abnormalities (Mears, Vessey, Andolšek, and Oken, 1969; Larsson-Cohn, Tengstrom, and Wide, 1969).

Therefore, in the present investigation we have reassessed the effects on tryptophan metabolism of combined oral contraceptives containing a low dose of oestrogen, and, as the effects of continuous lowdosage progestagen administration on tryptophan metabolism have not been reported, we have studied these in women taking megestrol acetate $0.5 \mathrm{mg}$ daily.

\section{Subjects and Methods}

Ten women were studied before they started to take an oral contraceptive, and the tests were then repeated after the administration of an oestrogenprogestagen preparation for 21 days, and again after three months. The preparations used and the number taking each one are given in Table I. A further 10 women were investigated when they had been taking a combined type of oral contraceptive for six to $\mathbf{1 8}$ months (Table II). Four subjects taking oral contraceptives were studied before and after the administration of pyridoxine hydrochloride, $20 \mathrm{mg}$ daily, for one month.

Tryptophan metabolism by four other subjects (Table II, nos. 3, 4, 8, 9) was assessed when they had been using an oral contraceptive for several months, and then at intervals after they had discontinued its use.

Five women were investigated when they had been taking megestrol acetate, $0.5 \mathrm{mg}$ daily, for three to 23 months (Table V).

The subjects fasted overnight, and the next morning $2 \mathrm{~g}$ L-tryptophan was taken orally, sus-

\begin{tabular}{lll}
\hline Oral Contraceptive & Oestrogen & Progestagen \\
\hline Minovlar & Ethinyl oestradiol $0.05 \mathrm{mg}$ & Norethisterone acetate $1 \mathrm{mg}$ \\
Gynovlar & Ethinyl oestradiol $0.05 \mathrm{mg}$ & Norethisterone acetate $3 \mathrm{mg}$ \\
Norinyl-1 & Mestranol $0.05 \mathrm{mg}$ & Norethisterone acetate $1 \mathrm{mg}$ \\
Minilyn & Ethinyl oestradiol $0.05 \mathrm{mg}$ & $\mathbf{1}$ \\
\hline
\end{tabular}

Table I Combined oestrogen-progestagen oral contraceptives used in the study 


\begin{tabular}{|c|c|c|c|c|c|c|}
\hline \multirow[t]{2}{*}{ Subject No. } & \multirow[t]{2}{*}{ Oral Contraceptive } & \multirow[t]{2}{*}{ Duration of Use (months) } & \multicolumn{4}{|c|}{ Excretion of Metabolite $(\mu \text { mole } / 24 \mathrm{hr})^{2}$} \\
\hline & & & $\boldsymbol{K}$ & $H K$ & $H A$ & $X A$ \\
\hline $\begin{array}{l}1 \\
2\end{array}$ & $\begin{array}{l}\text { Ovulen } 50^{2} \\
\text { Minovlar }\end{array}$ & 6 & $\begin{array}{l}139 \\
120\end{array}$ & $\begin{array}{l}216 \\
158\end{array}$ & $\begin{array}{l}45 \\
46\end{array}$ & $\begin{array}{l}365 \\
418\end{array}$ \\
\hline 3 & $\begin{array}{l}\text { Ovulen } 50 \\
\text { Minovlar }\end{array}$ & $\left.\begin{array}{l}5 \\
5\end{array}\right\}$ & 322 & 630 & 150 & 950 \\
\hline $\begin{array}{r}4 \\
5 \\
6 \\
7 \\
8 \\
9 \\
10\end{array}$ & $\begin{array}{l}\text { Ovulen } 50 \\
\text { Ovulen } 50 \\
\text { Minovlar } \\
\text { Norinyl-1 } \\
\text { Volidan }{ }^{3} \\
\text { Gynovlar } \\
\text { Norinyl-1 }\end{array}$ & $\begin{array}{l}11 \\
11 \\
13 \\
13 \\
13 \\
15 \\
18\end{array}$ & $\begin{array}{r}115 \\
48 \\
91 \\
187 \\
341 \\
110 \\
134\end{array}$ & $\begin{array}{r}101 \\
45 \\
176 \\
194 \\
693 \\
135 \\
220\end{array}$ & $\begin{array}{r}71 \\
40 \\
56 \\
130 \\
60 \\
110 \\
84\end{array}$ & $\begin{array}{l}312 \\
312 \\
514 \\
422 \\
715 \\
360 \\
346\end{array}$ \\
\hline Upper limit normal range & - & - & 66 & 67 & 56 & 137 \\
\hline
\end{tabular}

Table II Tryptophan metabolite excretions by women taking a combined type oral contraceptive for at least six months

${ }^{1}$ Ethinyl oestradiol $0.05 \mathrm{mg}$, ethynodiol diacetate $1 \mathrm{mg}$

${ }^{2} K=$ kynurenine; $H K=3$-hydroxykynurenine; $H A=3$-hydroxyanthranilic acid; $X A=$ xanthurenic acid

athinyl oestradiol $0.05 \mathrm{mg}$, mestranol acetate $4 \mathrm{mg}$

'Mean value plus twicestandard deviation for 10 women studied before treatment with an oral contraceptive

pended in a glass of milk. Urine was then collected for 24 hours and an aliquot stored at $-15^{\circ} \mathrm{C}$ until the analyses were carried out. Xanthurenic acid was determined by thin-layer chromatography on cellulose (Walsh, 1965), and kynurenine, 3-hydroxykynurenine, and 3-hydroxyanthranilic acid by the ion-exchange chromatography method of Heeley (1965).

Statistical examination of the results was by Student's $t$ test, differences giving $P=0.05$ being regarded as significant.

\section{Results}

After 21 days' treatment with a combined type of oral contraceptive there was a significant increase in the urinary xanthurenic acid excretion $(P<0.01$; Table III), only one of the 10 subjects not having an elevated excretion of this metabolite. However, the excretions of kynurenine, 3-hydroxykynurenine, and 3-hydroxyanthranilic acid were unchanged (Table III). By three months the xanthurenic acid excretions were considerably higher than they had been at $\mathbf{2 1}$ days, and there were also increases in themean values for the excretion of the other three metabolites, although, owing to the considerable degree of variance within the groups, these changes were not statistically significant.

The tryptophan metabolite excretions by the 10 patients who had been taking an oestrogen-containing preparation for six months or more are given in Table II. They all excreted grossly elevated levels of xanthurenic acid, all but one (no. 5) excreted markedly increased quantities of kynurenine and 3-hydroxykynurenine, and in six there was a raised excretion of 3-hydroxyanthranilic acid. Comparison of the excretion of metabolites after three months' treatment with the urinary levels of the women who had been taking an oral contraceptive for six months or longer (Table III) showed that prolonged administration of a preparation containing $0.05 \mathrm{mg}$ of oestrogen results in an accentuation of the metabolic disturbance, significant further increases occurring in the excretions of xanthurenic acid $(\mathrm{P}<0.01)$, kynurenine, and 3-hydroxykynurenine $(\mathrm{P}<0.05)$.

Table IV shows that treatment with $20 \mathrm{mg}$ pyridoxine hydrochloride daily for one month

\begin{tabular}{|c|c|c|c|c|}
\hline \multirow[t]{2}{*}{ Duration of Treatment } & \multicolumn{4}{|c|}{ Excretion of Metabolites ( $\mu$ mole/24 hr) } \\
\hline & $\boldsymbol{K}$ & $H K$ & $H \boldsymbol{A}$ & $X A$ \\
\hline $\begin{array}{l}\text { Before administration } \\
\text { Twenty-one days } \\
\text { Three months } \\
\text { Six to } 18 \text { months }\end{array}$ & $\begin{array}{c}32 \pm 17 \\
37 \pm 27 \\
74 \pm 80 \\
161 \pm 97^{2}\end{array}$ & $\begin{aligned} 33 & \pm 17 \\
47 & \pm 36 \\
80 & \pm 72 \\
287 & \pm 228^{1}\end{aligned}$ & $\begin{array}{l}28 \pm 14 \\
31 \pm 16 \\
49 \pm 35 \\
79 \pm 39^{2}\end{array}$ & $\begin{array}{c}61 \pm 38 \\
184 \pm 91^{1} \\
232 \pm 96^{2} \\
470 \pm 210^{2}\end{array}$ \\
\hline
\end{tabular}

Table III Changes in urinary excretion of tryptophan metabolites during administration of a low dose oestrogencontaining oral contraceptive

Differences from pretreatment value: ${ }^{1} \mathrm{P}<0.01 ;{ }^{2} \mathrm{P}<0.001$. 


\begin{tabular}{|c|c|c|c|c|c|c|}
\hline \multirow[t]{2}{*}{ Subject No. } & \multirow{2}{*}{$\begin{array}{l}\text { Duration of Contraceptive } \\
\text { Use (months) }\end{array}$} & & \multicolumn{4}{|c|}{ Excretion of Metabolites ( $\mu$ mole/24 hr) } \\
\hline & & & $\boldsymbol{K}$ & $H \boldsymbol{K}$ & $H A$ & $X A$ \\
\hline 1 & 6 & $\begin{array}{l}(a)^{1} \\
(b)^{2}\end{array}$ & $\begin{array}{r}139 \\
34\end{array}$ & $\begin{array}{r}216 \\
43\end{array}$ & $\begin{array}{l}45 \\
65\end{array}$ & $\begin{array}{r}365 \\
82\end{array}$ \\
\hline 11 & 3 & (a) & $\begin{array}{r}134 \\
29\end{array}$ & $\begin{array}{r}144 \\
32\end{array}$ & $\begin{array}{r}147 \\
32\end{array}$ & $\begin{array}{r}360 \\
96\end{array}$ \\
\hline 12 & 4 & $\begin{array}{l}\text { (a) } \\
\text { (b) }\end{array}$ & $\begin{array}{r}432 \\
43\end{array}$ & $\begin{array}{r}310 \\
50\end{array}$ & $\begin{array}{r}123 \\
41\end{array}$ & $\begin{array}{r}370 \\
50\end{array}$ \\
\hline 13 & 5 & $\begin{array}{l}\text { (a) } \\
\text { (b) }\end{array}$ & $\begin{array}{l}36 \\
24\end{array}$ & $\begin{array}{l}45 \\
20\end{array}$ & $\begin{array}{l}29 \\
26\end{array}$ & $\begin{array}{r}216 \\
38\end{array}$ \\
\hline
\end{tabular}

Table IV Effect of pyridoxine administration on tryptophan metabolism by women taking a combined type of oral contraceptive

'(a) Metabolite excretions when taking oral contraceptives alone

'(b) Metabolite excretions when taking oral contraceptive plus pyridoxine $\mathrm{HCl} 20$ mg daily for 1 month.
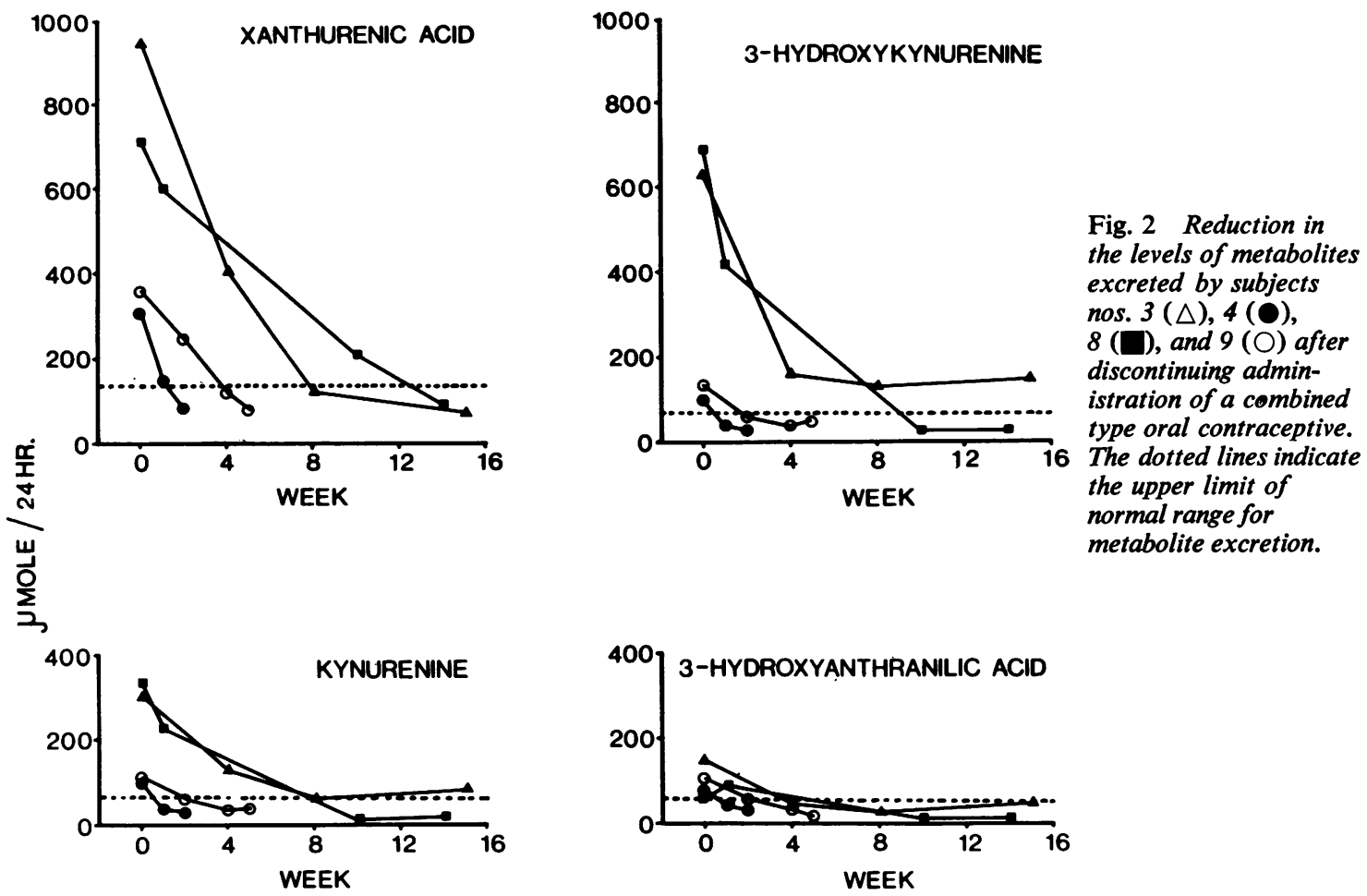

completely reverses the abnormal excretion of tryptophan metabolites by women receiving a combined type of oral contraceptive.

The rate of return of tryptophan metabolism to normal after discontinuing oral contraceptives is illustrated in Fig. 2, and it is apparent that there is an association between the severity of the initial abnormal excretion of metabolites and the time required for the levels to reach pretreatment values. One patient (no. 3) continued to excrete a high level of 3-hydroxykynurenine 15 weeks after stopping the use of an oral contraceptive.

The levels of tryptophan metabolites in the urine of five women taking megestrol acetate are given in Table V. Subject no. 14 had been using an oestrogencontaining oral contraceptive until three months before the metabolic studies, and it seems likely that the elevated excretions of kynurenine, 3-hydroxykynurenine, and 3-hydroxyanthranilic acid reflect a residual oestrogen effect. The xanthurenic acid 


\begin{tabular}{|c|c|c|c|c|c|}
\hline \multirow{2}{*}{$\begin{array}{l}\text { Subject } \\
\text { No. }\end{array}$} & \multirow{2}{*}{$\begin{array}{l}\text { Duration of } \\
\text { Use (mth) }\end{array}$} & \multicolumn{4}{|c|}{ Excretion of Metabolites ( $\mu$ mole $/ 24 \mathrm{hr}$ ) } \\
\hline & & $K$ & $H K$ & $H A$ & $X A$ \\
\hline 14 & 3 & 206 & 117 & 78 & 67 \\
\hline 15 & 14 & 58 & 36 & 69 & 58 \\
\hline 16 & 16 & 48 & 41 & 26 & 110 \\
\hline 17 & 18 & 62 & 45 & 55 & 62 \\
\hline 18 & 25 & 57 & 50 & 36 & 77 \\
\hline \multicolumn{2}{|c|}{ Upper limit normal range } & e 64 & 67 & 56 & 137 \\
\hline
\end{tabular}

Table V Tryptophan metabolism by women taking megestrol acetate

excretion was normal. Subject no. 15 appeared to excrete a slightly increased quantity of 3-hydroxyanthranilic acid, but the levels of the other metabolites were normal.

\section{Discussion}

The present study has shown that a reduction of the oestrogen component of the combined types of oral contraceptive to $0.05 \mathrm{mg}$ does not eliminate the abnormal metabolism of a $2 \mathrm{~g}$ tryptophan load which has previously been noted with Enavid-E, a preparation containing $0.1 \mathrm{mg}$ mestranol and $2.5 \mathrm{mg}$ norethynodrel (Price et al, 1967). An elevated urinary excretion of xanthurenic acid becomes apparent after only 21 days of treatment with a lowdose oestrogen oral contraceptive, although at this

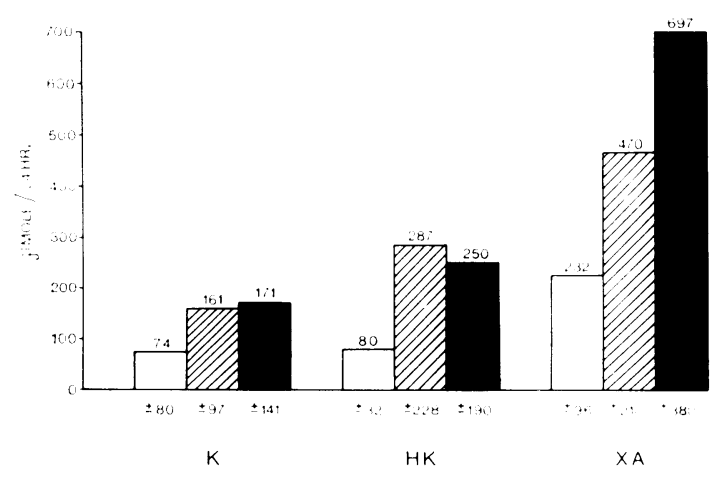

Fig. 3 Comparison of the excretion of kynurenine $(\mathrm{K})$, 3-hydroxykynurenine (HK), and xanthurenic acid (XA) by a group of women taking a low-dose oestrogen oral contraceptive $(0.05 \mathrm{mg}$ ethinyl oestradiol or mestranol) with the group taking Enavid-E (mestranol $0.1 \mathrm{mg}$ ) reported by Price et al (1967).

Values indicated are the means $\pm S D$.

Open blocks: low oestrogen preparation for three months; cross-hatched blocks: low oestrogen preparation for six to 18 months; solid black blocks: Enavid-E for several months. time the levels of the other metabolites are unchanged.

Prolonged administration of an oestrogen-containing oral contraceptive produces increased excretions of kynurenine, 3-hydroxykynurenine, and 3-hydroxyanthranilic acid, as well as of xanthurenic acid. Figure 3 compares the output of metabolites by women taking an $0.05 \mathrm{mg}$ dose of oestrogen for only three months or for six months or longer with the levels reported by Price et al (1967) in their study of women who had been receiving Enavid-E for several cycles. There is a higher excretion of xanthurenic acid by the Enavid-E-treated group compared with the subjects who had received the lower dose of oestrogen for six months or more, but the levels of kynurenine and 3-hydroxykynurenine are similar. The group of women treated with $0.05 \mathrm{mg}$ oestrogen for only three months excreted lower levels of these metabolites than the Enavid-E-treated women. These results suggest that the severity of the disturbance of tryptophan metabolism is influenced by both the dose of oestrogen in the oral contraceptive and by the duration of its administration.

Recently, Rose and McGinty (1970) have reviewed the possible mechanisms by which oestrogens may influence metabolism along the tryptophan-nicotinic acid pathway. It is suggested that these steroids both stimulate the activity of tryptophan oxygenase, the first and rate-limiting enzyme, and also inhibit the supernatant pyridoxal phosphate-dependent enzymes of the pathway, but not the mitochondrial aminotransferase which yields xanthurenic acid (Fig. 1). There is evidence from animal studies in support of both these possibilities (Braidman and Rose, 1971; Mason, Ford, and Wu, 1969).

Regardless of the precise biochemical mechanisms involved in the production of the metabolic disturbance, its correction by treatment with pyridoxine has been interpreted as indicating an increased requirement for this vitamin in women using oestrogen-containing oral contraceptives (Toseland and Price, 1969; Luhby et al, 1970).

The effect of oestrogens on tryptophan metabolism may be relevant to some of the other side effects of oral contraceptives, including mental depression, the appearance of rheumatic symptoms, and impaired glucose tolerance. There is considerable evidence that failure of normal brain 5-hydroxytryptamine synthesis from L-tryptophan may be important in the aetiology of depression (Curzon, 1969). Winston (1969) has suggested that in women who develop depression while taking an oral contraceptive, production of this amine is low due to inhibition of the pyridoxal phosphate-dependent decarboxylation step (Fig. 1), and Rose (1971) has recently reviewed the biochemical evidence in support of both this hypo- 
thesis, and the possibility that increased turnover of the tryptophan-nicotinic acid ribonucleotide pathway, due to oestrogen action, results in a lack of substrate for 5-hydroxytryptamine biosynthesis.

Abnormal tryptophan metabolism occurs in rheumatoid arthritis (McMillan, 1960; Bett, 1966), and rheumatic symptoms may develop during the use of oral contraceptives (Bole, Friedlander, and Smith, 1969; Spiera and Plotz, 1969). However, the precise mechanism for the elevated excretion of tryptophan metabolites in rheumatoid arthritis remains to be established, and so for the present the clinical significance of any association between abnormal tryptophan metabolism and rheumatic complaints in oral contraceptive-treated women is uncertain.

Wynn and Doar $(1966,1970)$ observed impaired oral glucose tolerance in over $75 \%$ of women using a combined type of oral contraceptive, and in $13 \%$ there was chemical diabetes mellitus. They drew attention to the elevated plasma cortisol levels which occur during oestrogen administration, and postulated that the changes in glucose tolerance in women receiving oral contraceptives result from exposure of the liver to high glucocorticoid concentrations. In a further paper, Doar and Wynn (1970) pointed out the similarity between the changes in glucose tolerance and pyruvate metabolism observed in nonobese subjects taking oestrogen-containing oral contraceptives and those seen in non-obese patients treated with glucocorticoids and obese non-diabetic patients not receiving steroids, and they suggested that the metabolic abnormality in all three situations results from excessive glucocorticoid activity. The high levels of corticosteroid-inducible enzymes in the livers of oestrogen-treated rats, and the changes in tryptophan metabolism in oestrogen-treated human subjects, women using oestrogen-containing oral contraceptives, and subjects treated with hydrocortisone (Rose and McGinty, 1968) provide strong indirect support for this hypothesis.

Impaired glucose tolerance may also be directly related to the abnormal tryptophan metabolism by women taking oral contraceptives. The elevated urinary levels of xanthurenic acid which were observed in the present study are presumably accompanied by high plasma and liver concentrations of this metabolite, and experimental work by Kotake et al (1968) has shown that xanthurenic acid is capable of forming a complex with insulin which reduces the effect of this hormone on the blood glucose level by about $50 \%$. The clinical significance of this interesting observation remains to be established.

Impaired glucose tolerance may persist for six weeks or more after withdrawal of an oral contra- ceptive (Wynn and Doar, 1970) and so it is especially noteworthy that abnormal tryptophan metabolism has been demonstrated eight to 15 weeks after discontinuing the administration of these preparations.

Studies of individual steroids indicate that the abnormalities of both carbohydrate and tryptophan metabolism in women using the combined types of oral contraceptives are produced by the oestrogen component alone (Di Paola, Robin, and Nicholson, 1970; Rose, 1966). Consistent with this is the present observation that the continuous administration of the progestagen megestrol acetate in low dosage for contraceptive purposes does not produce any significant change in tryptophan metabolism, and also that in a recent study of this steroid it has been shown to have no effect upon glucose tolerance (Adams and Wynn, 1971). In addition, we have found that another $17 \alpha$-hydroxyprogesterone derivative, medroxyprogesterone acetate, does not alter tryptophan metabolism (unpublished data).

We are indebted to Professor Victor Wynn for his interest, and for allowing us to study his patients. This work was supported by a grant from the Medical Research Council and by contract no. Ph-43-67-1344 from the United States National Institutes of Health.

\section{References}

Adams, P., and Wynn, V. (1971). Submitted for publication.

Bett, I. M. (1962). Metabolism of tryptophan in rheumatoid arthritis. Ann. rheum. Dis., 21, 63-69.

Bole, G. G., Jr., Friedlaender, M. H., and Smith, C. K. (1969). Rheumatic symptoms and serological abnormalities induced by oral contraceptives. Lancet, 1, 323-326.

Braidman, I. P., and Rose, D. P. (1971). Effects of sex hormones on three glucocorticoid-inducible enzymes concerned with amino acid metabolism in rat liver. Endocrinology, 89, 1250-1255.

Brown, R. R., Rose, D. P., Price, J. M., and Woolf, H. (1969). Tryptophan metabolism as affected by anovulatory agents. Ann. N.Y. Acad. Sci., 166, 44-56.

Curzon, G. (1969). Tryptophan pyrrolase-a biochemical factor in depressive illness? Brit. J. Psychiat., 115, 1367-1374.

Di Paola, G., Robin, M., and Nicholson, R. (1970). Estrogen therapy and glucose tolerance test. Amer. J. Obstet. Gynec., 107, 124-132.

Doar, J. W. H., and Wynn. V. (1970). Effects of obesity, glucocorticoid, and oral contraceptive therapy on plasma glucose and blood pyruvate levels. Brit. med. J., 1, 149-152.

Heeley, A. F. (1965). The effect of pyridoxine on tryptophan metabolism in phenylketonuria. Clin. Sci., 29, 465-473.

Kotake, Y., Sotokawa, T., Murakami, E., Hisatake, A., Abe, M., and Ikeda, Y. (1968). Studies on the xanthurenic acid-insulin complex. II. Physiological activities. J. Biochem. (Tokyo), 63, 578-581.

Larsson-Cohn, U., Tengström, B., and Wide, L. (1969). Glucose tolerance and insulin response during daily continuous lowdose oral contraceptive treatment. Acta endocr. (Kbh), 62, 242-250.

Luhby, A. L., Davis, P., Murphy, M., Gordon, M., Brin, M., and Spiegel, H. (1970). Phyridoxine and oral contraceptives. (Letter to the Editor). Lancet, 2, 1083.

McMillan, M. (1960). The identification of a fluorescent reducing substance in the urine of patients with rheumatoid arthritis. J. clin. Path., 13, 140-148.

Mason, M., Ford, J., and Wu, H. L. C. (1969). Effects of steroids and 
nonsteroid metabolites on enzyme conformation and pyridoxal phosphate binding. Ann. N.Y. Acad. Sci., 166, 170-183.

Mears, E., Vessey, M. P., Andolsek, L., and Oven, A. (1969). Preliminary evaluation of four oral contraceptives containing only progestogens. Brit. med. J., 2, 730-734.

Price, J. M., Brown, R. R. and Yess, N. (1965). Testing the functional capacity of the tryptophan-niacin pathway in man by analysis of urinary metabolites. Advanc. metab. Dis., 2, 159-225.

Price, J. M., Thornton, M. J., and Mueller, L. M. (1967). Tryptophan metabolism in women using steroid hormones for ovulation control. Amer. J. clin. Nutr., 20, 452-456.

Rose, D. P. (1965). Tryptophan metabolites. In report of conference sponsored by Institute of Urology and Cancer Research. Brit. med.J., $1,1432$.

Rose, D. P. (1966). The influence of oestrogens on tryptophan metabolism in man. Clin. Sci., 31, 265-272.

Rose, D. P. (1972). Aspects of tryptophan metabolism in health and disease: a review. J. clin. Path., 25, 17-25.

Rose, D. P., and McGinty, F. (1968). The influence of adrenocortical hormones and vitamins upon tryptophan metabolism in man. Clin. Sci., 35, 1-9.
Rose, D.P., and McGinty, F.(1970). The effect of steroid hormones on tryptophan metabolism. In Advances in Steroid Biochemistry and Pharmacology, edited by M. H. Briggs. vol. 1, pp. 97-136. Academic Press, London and New York.

Scowen, E. F. (1969). Oral contraceptives containing oestrogens. (Correspondence). Brit. med. J., 4, 744.

Spiera, H., and Plotz, C. M. (1969). Rheumatic symptoms and ora contraceptives. (Letter to the Editor). Lancet, 1, 571-572.

Toseland, P. A., and Price, S. (1969). Tryptophan and oral contraceptives. (Correspondence). Brit. med. J., 1, 777.

Walsh, M. P. (1965). Separation and estimation of tryptophannicotinic acid metabolites in urine by thin-layer chromatography. Clin. chim. Acta, 11, 263-267.

Winston, F. (1969). Oral contraceptives and depression. (Letter to the Editor). Lancet, 1, 1209.

Wynn, V., and Doar, J. W. H. (1966). Some effects of oral contraceptives on carbohydrate metabolism. Lancet, 2, 715-719.

Wynn, V., and Doar, J. W. H. (1970). Effects of oral contraceptives on carbohydrate metabolism. J. clin. Path., 23, Suppl. (Ass. Clin. Path), 3, 19-36.

\section{Reports and Bulletins prepared by the Association of Clinical Biochemists}

The following reports and bulletins are published by the Association of Clinical Biochemists. They may be obtained from The Administrative Office, Association of Clinical Biochemists, 7 Warwick Court, Holborn, London, WC1R 5DP. The prices include postage, but air mail will be charged extra. Overseas readers should remit by British Postal or Money Order. If this is not possible the equivalent of 50p is the minimum amount that can be accepted.

SCIENTIFIC REPORTS

3 Automatic Dispensing Pipettes. An assessment of 35 commercial instruments 1967 P. M. G. BROUGHTON, A. H. GOWENLOCK, G. M. WIDDOWSON, and K. A. AHLQUIST 85p (\$2)

4 An Evaluation of five Commercial Flame Photometers suitable for the Simultaneous Determination of Sodium and Potassium March 1970 P. M. G. BROUGHTON and J. B. DAWSON $85 p(\$ 2)$

\section{SCIENTIFIC REVIEWS}

1 The Assessment of Thyroid Function March 1971 F. V. FLYNN and J. R. HOBBS $62 \frac{1}{\mathrm{p}} \mathrm{p}(\$ 1.50)$

\section{TECHNICAL BULLETINS}

9 Determination of Urea by AutoAnalyzer November

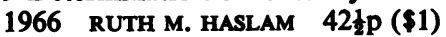

11 Determination of Serum Albumin by AutoAnalyzer using Bromocresol Green October 1967 B. E. NORTHAM and $G$. $M$. WIDDOwSON $42 \frac{1}{2} p(\$ 1)$

13 An Assessment of the Technicon Type II Sampler Unit March 1968 B. C. GRAY and G. K. MCGOWAN 421 $\mathrm{p}(\$ 1)$

14 Atomic Absorption Spectroscopy. An outline of its principles and a guide to the selection of instruments May 1968 J. B. DAWSON and P. M. G. BROUGHTON $42 \mathrm{t} p(\$ 1)$
15 A Guide to Automatic Pipettes (2nd edition) June

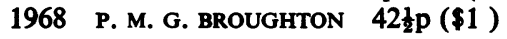

16 A Guide to Automation in Clinical Chemistry May

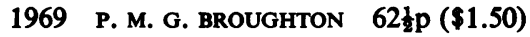

17 Flame Photometers (2nd edition) 1969 P. WILDING $62 \mathrm{t} p(\$ 1.50)$

18 Control Solutions for Clinical Biochemistry (4th edition) March 1970 P. M. G. BROUGHTON 62tp (\$1.50)

19 Spectrophotometers. A comparative list of low-priced instruments readily available in Britain May 1970 C. E. WILDE and P. SEWELL 62tp (\$1.50)

20 Quantities and Units in Clinical Biochemistry June 1970 P. M. G. BROUGHTON 62 $\frac{1}{2} \mathrm{p}(\$ 1.50)$ More than 30 copies in units of 10 at 20p

21 Filter Fluorimeters: A comparative list of 18 instruments September 1970 H. BRAUNSBERG and S. S. BROWN 62tp (\$1.50)

22 Bilirubin standards and the Determination of Bilirubin by Manual and Technicon AutoAnalyzer Methods. January 1971 BARBARA BILLING, RUTH HASLAM and N. WALD $62 \frac{1}{2} \mathrm{p}(\$ 1.50)$

23 Interchangeable Cells for Spectrophotometers and Fluorimeters September 1971 E. S. BROWN and A. H. GOWENLOCK $62 \mathrm{t} \mathrm{p}(\$ 1.50)$ 